\title{
Morel-Lavallée Lesion: A Case Report of a Large Post-Traumatic Subcutaneous Lumbar Hematoma and Literature Review
}

\author{
Dominique N’Dri Oka*, Daouda Sissoko, Alban Slim Mbende \\ Neurosurgery Unit, Yopougon Teaching Hospital, Abidjan, Côte d'Ivoire

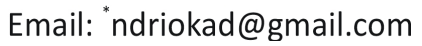

Received 9 November 2015; accepted 8 January 2016; published 12 January 2016

Copyright (C) 2016 by authors and Scientific Research Publishing Inc.

This work is licensed under the Creative Commons Attribution International License (CC BY). http://creativecommons.org/licenses/by/4.0/

c) (i) Open Access

\begin{abstract}
Morel-Lavallée Lesions (MLL), described in 1863 by French surgeon Victor-Auguste-François MorelLavallée, are rare posttraumatic closed degloving injuries, occurring as a result of tangential sheer forces, in which the skin and subcutaneous tissue separate abruptly from the underlying deep fascia, causing fluid collection with liquefied fat. A 31-year-old policeman involved in a road traffic accident, presented with a gradually expanding lumbar swelling, which was soft, fluctuant and painful with contused skinon examination. Computed Tomography (CT) scan of the lumbar spine revealed a large subcutaneous hematoma on axial view, extending from the 12th thoracic vertebra down to the first sacral vertebra. There was no skeletal lesion. The treatment consisted of surgical excision/drainage of the collection followed by continuous suction with drainage tubes for two days. The collection is completely resolved; the patient made a full recovery and has been asymptomatic. Since there was a history of blunt trauma and given the nature and the location of the collection over osseous prominences, we report this rare case of a large posttraumatic lumbar hematoma diagnosed on clinical and CT scanning grounds as a Morel-Lavallée lesion. The patient was informed that non-identifying information from the case would be submitted for publication, and he provided consent.
\end{abstract}

\section{Keywords}

Morel-Lavallée Lesions (MLL), Subcutaneous Hematoma, Lumbar Trauma

\section{Introduction}

Morel-Lavallée Lesions (MLL) are uncommon posttraumatic injuries that occur as a result of compression and

${ }^{*}$ Corresponding author.

How to cite this paper: Oka, D.N., Sissoko, D. and Mbend, A.S. (2016) Morel-Lavallée Lesion: A Case Report of a Large Post-Traumatic Subcutaneous Lumbar Hematoma and Literature Review. Open Journal of Modern Neurosurgery, 6, 29-36. http://dx.doi.org/10.4236/ojmn.2016.61006 
sheer forces, separating the hypodermis from the underlying deep fascia. This mechanism of injury whereby the subcutaneous tissue is torn off the underlying fascia is referred to as internal degloving [1]. In fact, a degloving injury is a type of avulsion in which an extensive section of skin is stripped off the underlying tissue, severing its vascular and lymphatic supply. The distorted vascular and lymphatic supply of the injured tissue in the MLL precipitates fluid collection in this newly created potential space, which subsequently, fills with blood, lymph and necrotic fat [1]-[8]. If not treated, inflammatory reaction will follow and transform granulation tissue into a fibrous capsule [5]. This fibrous capsule impedes the absorption of the collection and is thought to be the cause of recurrent fluid collection even after drainage. Reports of clinicians failing to diagnose MLL due to inconsistent clinical manifestations have been documented in the literature [8]. Kottmeir et al. reported that the diagnosis of MLLs is missed up to $44 \%$ of the time [9]. It is the authors' view that early detection and treatment of MLLs is paramount to prevent complications such as recollection, chronic pain and infection-related morbidity. Magnetic resonance imaging (MRI) is by far the modality of choice for detecting and revealing the location and size of these lesions [10] [11]. But other imaging modalities such as CT scan and ultrasound are also valuable diagnostic tools [9] [11]. Surgical excision/drainage of the collection and/or debridement has been advocated as the best method of treatment [1] [6]-[12]. Lumbar locations of MLL, let alone large ones, have been rarely reported in the literature. Given the clinical significance of this rare case, we present this patient with a large lumbar MLL treated successfully with surgical excision/drainage, followed by a thorough literature review on Medline and Google scholar database.

\section{Case Report}

Mr. TKJ a 31-year-old police officer was admitted to Accident and Emergency for the management of multiple injuries following a road traffic accident. The patient, who was on a routine night patrol, was sitting behind a full speed HILUX $4 \times 4$ single cabin adapted patrol vehicle, when a false manoeuvre by the driver propelled him onto a hard surface. A blunt trauma to the back associated with a traumatic brain injury and initial loss of consciousness occurred. On arrival, the patient complained of severe headache and pain over the thoracic and lumbar spine. Clinical examination revealed a fully alert patient with a BP of $140 / 100 \mathrm{~mm} \cdot \mathrm{Hg}$ and a pulse of 72 beat/min. A soft, fluctuant and painful mass over the lumbar spine with contused skin was gradually increasing in volume and preventing any comfortable supine position (Figure 1). There was no motor, sensory or sphincter deficit.

CT scan of the thoraco-lumbar spine demonstrated a large $(81.5 \mathrm{~mm} \times 38.5 \mathrm{~mm})$ spontaneously hyperdense subcutaneous collection on axial view, extending from the $12^{\text {th }}$ thoracic vertebra down to the first sacral vertebra, consistent with a subcutaneous hematoma (Figure 2). There was no skeletal lesion. A concomitant brain CT scan showed hemorrhagic contusion of the left temporal lobe associated with subarachnoid haemorrhage (Figure 3).

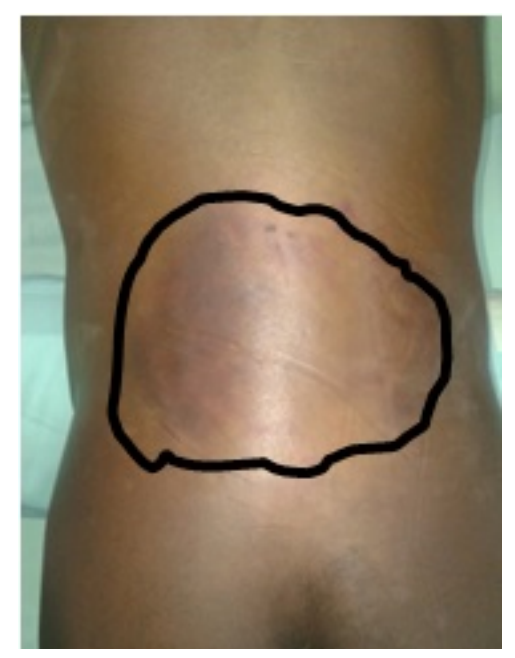

Figure 1. Shows lumbar swelling with contused skin. 

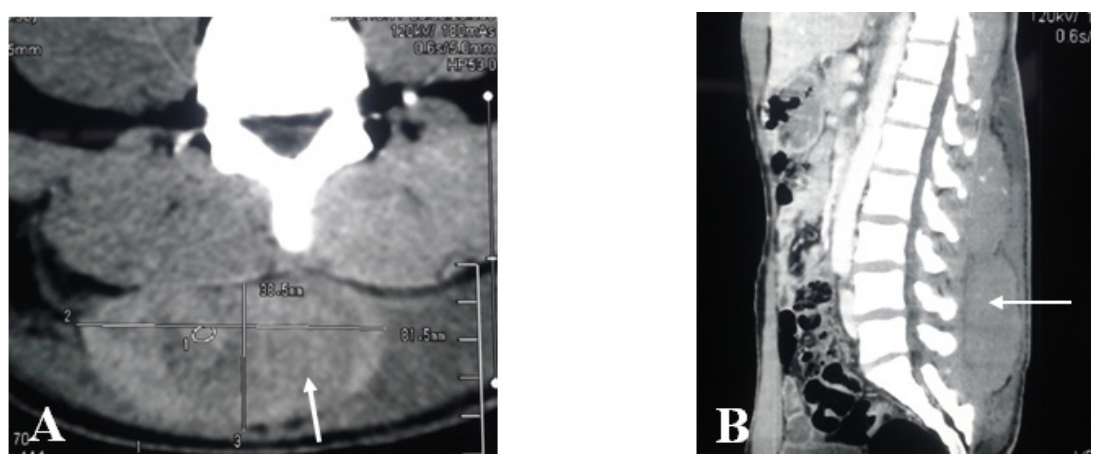

Figure 2. Thoraco-lumbar CT scan shows on axial view (A) a large $81.5 \mathrm{~mm} \times 38.5$ mm collection and on sagittal view (B) the collection extending from T12 down to S1.

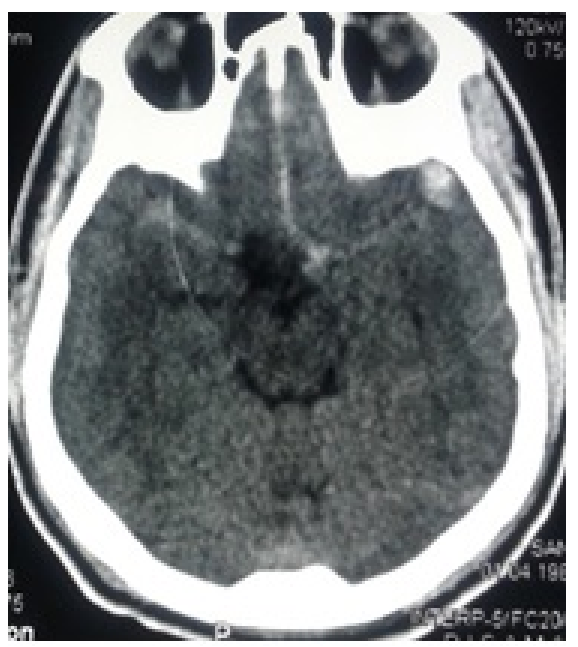

Figure 3. Axial view of the patient brain CT scan showing hemorrhagic contusion of the left temporal lobe with subarachnoid haemorrhage.

Basic coagulation screening tests revealed a prothrombin time (PT) of $72 \%$, an activated partial thromboplastin time (aPTT) of 30 seconds, a fibrinogen of $2.9 \mathrm{~g} / \mathrm{l}$ and a platelet count of $191 \times 10^{3} / \mathrm{mL}$.

Surgical excision/drainage of the collection was warranted, given the large volume of the hematoma and the discomfort for the patient quality of life. Surgery was performed under general anaesthetics 24 hours after the accident. We performed a $3 \mathrm{~cm}$ incision over the centre of the collection, patient being prone. The opening of the cavity provoked oozing of blackish blood mixed with clots (Figure 4). A total of $230 \mathrm{~mL}$ of sanguineous fluid was drained during surgery and the cavitywas thoroughly cleaned with $120 \mathrm{~mL}$ of normal saline solution (Figure 5). The wound was closed over drainage tubes that were attached to a continuous suction and left in place for 48 hours. Brain lesions were managed with supportive measures. Removal of drain tubes 48 hours later, expressed $350 \mathrm{~mL}$ of serosanguineous fluid (Figure 6). The postoperative course was uneventful and the patient was discharged 72 hours after surgery. Twenty six months after surgery, the postoperative course was uneventful.

\section{Discussion}

Posttraumatic hematoma or cyst between the subcutaneous tissue and the underlying deep fascia is known as Morel-Lavallée lesions (MLL). Although a well-known entity, there are no statistical data available in the literature to support the prevalence of MLL. These lesions were described for the first time in themid- $19^{\text {th }}$ century by French surgeon Victor-Auguste-FrançoisMorel-Lavallée [1] [2] [8]. In his 1863 papyrus, Morel-Lavallée referred to posttraumatic closed degloving injuries involving the trochanteric region as Morel-Lavallée lesions [1] [2]. In recent years, however, posttraumatic lesions with similar pathophysiology involving other anatomical locations had been described since as MLL [2] [6] [8] [15] [17]-[21]. In an unprecedented review of the literature 


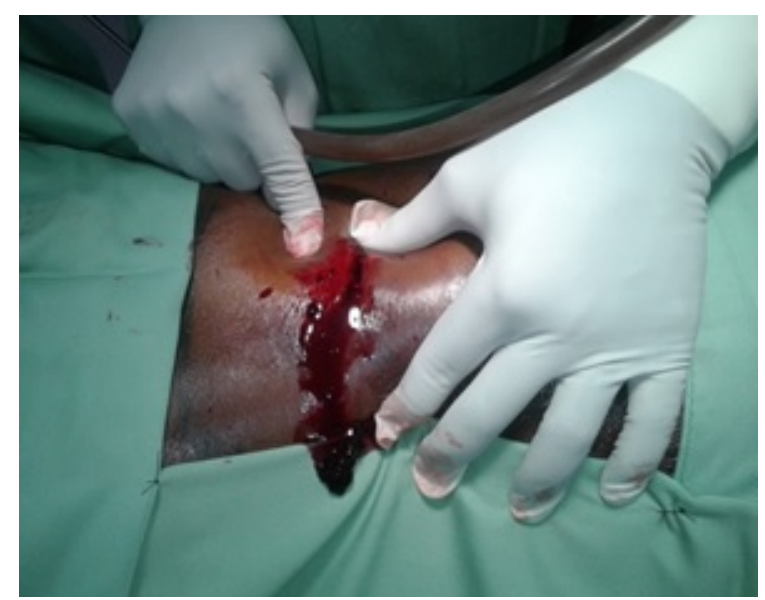

Figure 4. Shows blackish blood mixed with clots oozing from the cavity during surgery.

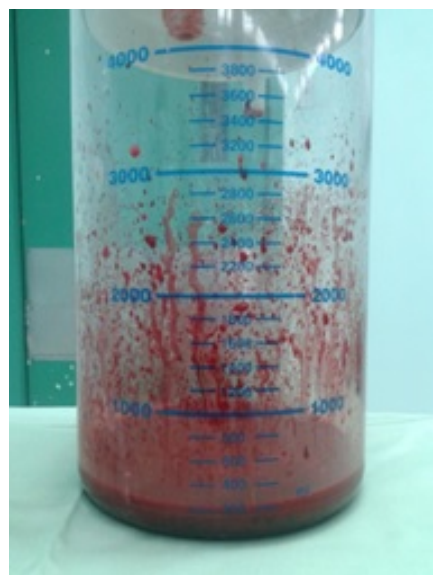

Figure 5. Shows $230 \mathrm{~mL}$ of sanguineous fluid drained during surgery mixed with $120 \mathrm{~mL}$ of normal saline.

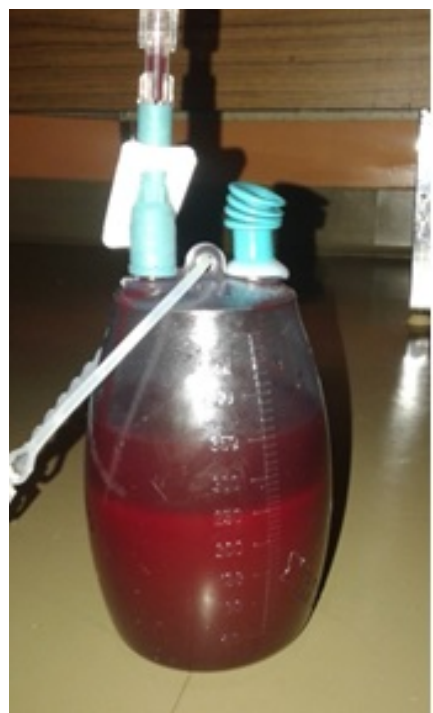

Figure 6. Shows $350 \mathrm{~mL}$ of serosanguineous fluid expressed from the continuous suction. 
which culminated to a total of 204 lesions in 195 patients from 14 different countries, Vanhegan I et al. found that the most common location was the greater trochanter/hip (36\%), followed by the thigh (24\%) and the pelvis (19\%) [22]. other locations include the knee, lumbosacral region, scalp, abdominal wall, the buttock and the calf. Lumbar location of MLL is rare and large collections extending from T12 to S1 are seldom found as was the case of our patient, making this case clinically significant.

MLL have been described in males and females alike, indiscriminative of age [5] [7] [8] [20]. Some authors argue that cases of female MLL are significantly higher compared with male ones given the pattern of fat distribution in female [24] [25]. and anatomical and molecular basis of fasciae [26].

High-velocity trauma such as road traffic accidents are the most common causes of MLL, but low kinetic crush injuries occurring during sports activities may also result to MLL [4] [8] [18] [19] [24] [27]. Cases of MLL associated with skeletal injuries have been reported [24]. Our patient was fortunate enough to have not sustained skeletal injuries, despite being involved in a high kinetic trauma. Kontis et al. reported a case of a 74-year-oldmale patient with a cystic lesion of the lateral surface of the left thigh in which a meticulous history acquisition failed to ascertain an alleged mechanism of injury [28].

The pathophysiology of MLL has been extensively documented by previous authors [1] [3]-[5] [25] [29]. When crushing blunt trauma to the skin occurs, tangential shear forces peel back the subcutaneous fat from the deep fascia, severing the subcutaneous rich vascular and lymphatic supply [26]. The distorted vascular and lymphatic supply precipitates fluid collection in this newly created potential space, which subsequently, fills with blood, lymph and necrotic fat. Generally speaking, Morel-Lavallée lesions develop in four stages. Initially, depending on the shear forces of the trauma, a simple serous collection known as seroma or a real hematoma will occur. Subsequently, as the lesion evolves, a more complex and heterogeneous collection made of blood, lymph and necrotic fat will develop. The collection can settle or gradually increasing in size, in rare cases, is responsible for hypovolemic shock with potential life threatening consequences, especially in multiple trauma patients [30]. As the haemoglobin breaks down gradually into its by-products, the collection liquefies. If not treated, inflammatory reaction will follow and transform granulation tissue into a fibrous capsule, which will impede the absorption of the collection, and is thought to be the potential pathophysiology mechanism governing persistent fluid collection after drainage [5].

Clinical signs are frequently seen in the hours following trauma as was the case of our patient [3]. But in a third of cases, the diagnosis is missed initially until clinical signs become apparent weeks, months or even years after the initial trauma [5] [6] [9] [22] [31] [32]. The hallmark physical finding of MLL is a palpable, soft, fluctuant mass over the area of degloving [1] [3] [8]. Other signs of injury such as ecchymosis, bruising, dermabrasion, contusion, tire marks, friction burns, excoriations, and hypoesthesia (by crushing of nerve endings) over the area of degloving may also be present [19] [25]. Our patient had distinctive fluctuant swelling and contusion over the area of degloving. MLL could be isolated or associated with underlying skeletal injuries [24] [33]. In our case, there was no skeletal lesion associated with the degloving injury.

Recent advances in imaging technology have significantly improved early detection of MLL, and Magnetic resonance imaging (MRI) is by far the modality of choice for detecting and revealing the location and size of these lesions [9]-[11]. Mellado and Bencardio described 6 types of lesions based on their MRI characteristics [11]. Other imaging modalities such as CT scan and ultrasound are valuable diagnostic tools [9] [11]. A fluidfluid level resulting from sedimentation of blood by-products on CT scan for instance is indicative of MLL. Moreover, a compressible, hypoechoic or anechoic to isoechoic fluid collection between deepsubcutaneous fat and fascia associated with hyperechoic fat nodules on ultrasound exam isrepresentative of MLL until proven otherwise. Due to inadequate hospital equipment, our patient could not undergo an MRI scan urgently, but instead underwent an urgent CT scan which showed a large, spontaneously hyperdense subcutaneous collection which was consistent with a subcutaneous hematoma or MLL. This is significant, because our patient had the largest posttraumatic lumbar subcutaneous hematoma ever reported. Massive MLL reported in the literature occur mostly in the medial thigh or knee region [9] [21].

MLL should be differentiated from muscle contusion, fat necrosis, pseudolipoma, subcutaneous abscess, coagulopathy-related hematoma, knee bursitis and soft-tissue tumor [5] [22] [31] [32]. Apart from muscle contusion and coagulopathy-related hematoma, MLL mimicking other lesions are usually seen in the subacute or chronic stage. A meticulous history taking combined with a thorough clinical examination and modern imaging modalities should aid in the diagnosis of MLL. Our patient had a recent history of trauma hours before his admission and his coagulopathy profile was normal. 
The treatment of these lesions is still not well codified [3]. It should be tailored according to the type, age and size of lesions. Many authors have advocated that timely intervention via incision/drainage with or without debridement of MLL should be warranted, as soon as the collection has been ascertained, to avoid potential complications [5]. Nickerson et al. showed in a retrospective study of 87cases of MLL that 83\% of lesions thatdrained more than $50 \mathrm{~mL}$ on subcutaneous aspiration were doomed to reoccur if not treated surgically [34] [35]. Generally speaking, treatment options available to physician include percutaneous aspiration, incision/drainage, synthetic adhesive, simple bandages or talc, doxycycline, erythromycin, alcohol, bleomycin, tetracycline sclerodesis [3] [20] [35]. Surgical excision/drainage of the collection and/ordebridement has been advocated as the best method of treatment [1] [3] [5] [12] [13] [15] [16] [21] [23] [24]. But in persistent cases, talc or doxycycline sclerodesis combined with compressive bandages have been used efficiently [20] [35]. Conventional wisdom requires acute injuries to be treated conservatively using compression bandages with or without sclerotherapy. If this fails, percutaneous aspiration is warranted. An incision/drainage is indicated when the above proves ineffective. For chronic injuries, first line of management would be percutaneous aspiration or surgical drainage/debridement combined with sclerotherapy to prevent postoperative hematoma and risks of secondary infection. Our patient had a large hematoma which was treated successfully with surgical excision/drainage.

A one-month follow-up did not yield any clinical sign of recollection or infection. Due to our inadequate hospital equipment and general economic hardship, our patient could not afford to undergo a control CT scan. Nonetheless, it’s the authors' view that the patient made a full recovery and since has been asymptomatic.

\section{Conclusion}

MLL is a rare entity. Large lumbar MLL is seldom found. MRI is by far the best diagnostic tool. But CT and ultrasound scans can play a pivotal role in detecting MLL, as was the case of our patient. Timely intervention via incision/drainage when the collection is ascertained should remain the first therapeutic tool in order to prevent potential complications. Emergency physicians and radiologists should become familiar with MLL in order to mitigate the dreadful impact of missed and delayed diagnosis.

\section{Conflict of Interest}

The authors confirm that this article content has no conflict of interest.

\section{References}

[1] Morel-Lavallée, M. (1863) Decollements traumatiques de la peau et des couches sous-jacentes. Archives générales de Médecine, 1, 20-38, 172-200, 300-332.

[2] Zhong, B., Zhang, C. and Luo, C.-F. (2014) Percutaneous Drainage of Morel-Lavallée Lesions When the Diagnosis Is Delayed. Canadian Journal of Surgery, 5, 356-357. http://dx.doi.org/10.1503/cjs.034413

[3] Sawkar, A.A., Swischuk, L.E. and Jadhav, S.P. (2011) Morel-Lavallee Seroma: A Review of Two Cases in the Lumbar Region in the Adolescent. Emergency Radiology, 18, 495-498. http://dx.doi.org/10.1007/s10140-011-0975-2

[4] Power, M.L., Hatem, S.F. and Sundaram, M. (2007) Morel-Lavallée Lesion. Orthopedics, 30, 322-323.

[5] Tresley, J., Jose, J., Saraf-Lavi, E. and Sklar, E. (2014) Sacral Morel-Lavallée Lesion: A Not-So-Rare Diagnosis. The Neuroradiology Journal, 27, 755-758. http://dx.doi.org/10.15274/nrj-2014-10088

[6] Hefny, A.F., Kaka, L.N., Salim El, N.A. and Al Khoury, N.N. (2015) Unusual Case of Life Threatening Subcutaneous Hemorrhage in a Blunt Trauma Patient. International Journal of Surgery Case Reports, 15, 119-122. http://dx.doi.org/10.1016/j.ijscr.2015.08.035

[7] Hudson, D.A., Knottenbelt, J.D. and Krige, J.E. (1992) Closed Degloving Injuries: Results Following Conservative Surgery. Plastic \& Reconstructive Surgery, 89, 853-855. http://dx.doi.org/10.1097/00006534-199205000-00013

[8] Benjamin, M. (2009) The Fascia of the Limbs and Back-A Review. Journal of Anatomy, 214, 1-18. http://dx.doi.org/10.1111/j.1469-7580.2008.01011.x

[9] Mellado, J.M. and Bencardino, J.T. (2013) Morel-Lavallée Lesion: Review with Emphasis on MR Imaging. Magnetic Resonance Imaging Clinics of North America, 13, 775-782. http://dx.doi.org/10.1016/j.mric.2005.08.006

[10] Medverd, J.R., Ngo, A.V. and Bhargava, P. (2011) An Unusual Cause of Persistent Subcutaneous Fluid Collection. The British Journal of Radiology, 84, 864-866. http://dx.doi.org/10.1259/bjr/29764457

[11] Gummalla, K.M., George, M. and Dutta, R. (2014) Morel-Lavallee Lesion: Case Report of a Rare Extensive Degloving Soft Tissue Injury. Ulusal Travma ve Acil Cerrahi Dergisi, 20, 63-65. http://dx.doi.org/10.5505/tjtes.2014.88403 
[12] Moran, D.E., Napier, N.A. and Kavanagh, E.C. (2012) Lumbar Morel-Lavallée Effusion. The Spine Journal, 12, 11651166. http://dx.doi.org/10.1016/j.spinee.2012.11.019

[13] Tsur, A., Galin, A., Kogan, L. and Loberant, N. (2006) Morel-Lavallee Syndrome after Crush Injury. Harefuah, 145, 111-113.

[14] Luta, V., Enache, A. and Costea, C. (2010) Posttraumatic Morel-Lavallée Seroma-Clinic and Forensic Implications. Romanian Journal of Legal Medicine, 18, 31-36. http://dx.doi.org/10.4323/rjlm.2010.31

[15] Tejwani, S.G., Cohen, S.B. and Bradley, J.P. (2007) Management of Morel-Lavallee Lesion of the Knee: TwentySeven Cases in the National Football League. The American Journal of Sports Medicine, 35, 1162-1167. http://dx.doi.org/10.1177/0363546507299448

[16] Weiss, N.A., Jeremiah, J.J. and Shane, B.A. (2015) Morel-Lavallée Lesion Initially Diagnosed as Quadriceps Contusion: Ultrasound, MRI, and Importance of Early Intervention. Western Journal of Emergency Medicine, 16, 438-441. http://dx.doi.org/10.5811/westjem.2015.3.25148

[17] Hak, D.J., Olson, S.A. and Matta, J.M. (1997) Diagnosis and Management of Closed Internal Degloving Injuries Associated with Pelvic And Acetabular Fractures: The Morel-Lavallee Lesion. Journal of Trauma, 42, 1046-1051. http://dx.doi.org/10.1097/00005373-199706000-00010

[18] Jalota, L., Ukaigwe, A. and Jain, S. (2015) Diagnosis and Management of Closed Internal Degloving Injuries: The Morel-Lavallée Lesion. Journal of Emergency Medicine, 49, e1-e4. http://dx.doi.org/10.1016/j.jemermed.2014.12.084

[19] Kumar, S., Hasan, R., Kadavigere, R., Maddukuri, S. and Puppala, R. (2015) Morel-Lavallée Lesion (MLL) Mimicking A Soft Tissue Neoplasm. Journal of Clinical and Diagnostic Research, 9, TD1-TD2. http://dx.doi.org/10.7860/jcdr/2015/13208.5793

[20] Bansal, A., Bhatia, N., Singh, A. and Singh, A.K. (2013) Doxycycline Sclerodesis as a Treatment Option for Persistent Morel-Lavallée Lesions. Injury, 44, 66-69. http://dx.doi.org/10.1016/j.injury.2011.11.024

[21] Yilmaz, A. and Yener, O. (2013) Giant Post-Traumatic Cyst after Motorcycle Injury: A Case Report with Review of the Pathogenesis. Prague Medical Report, 114, 123-127. http://dx.doi.org/10.14712/23362936.2014.30

[22] Vanhegan, I., Dala-Ali, B., Verhelst, L., Mallucci, P. and Haddad, F.S. (2012) The Morel Lavallee Lesion as a Rare Differential for Recalcitrant Bursitis of the Knee: Case Report and Literature Review. Case Reports in Orthopedics, 2012, Article ID: 593193. http://dx.doi.org/10.1155/2012/593193

[23] Bonilla-Yoon, I., Masih, S., Patel, D., White, E.A., Levine, B.D., Chow, K., et al. (2014) The Morel-Lavallée Lesion: Pathophysiology, Clinical Presentation, Imaging Features, and Treatment Options. Emergency Radiology, 21, 35-43. http://dx.doi.org/10.1007/s10140-013-1151-7

[24] De Montbrun, S., Khalili, K., MacLellan, S. and Easson, A. (2012) Morel-Lavallee Lesion of the Lower Back Mimicking an Abscess: A Case Report. Surgical Science, 3, 213-215. http://dx.doi.org/10.4236/ss.2012.34041

[25] Kumar, Y., Hooda, K., Lo, L. and Karol, I. (2015) Morel-Lavallée Lesion: A Case of an American Football Injury. Connecticut Medicine, 79, 477-478.

[26] Rha, E.Y., Kim, D.H., Kwon, H. and Jung, S.N. (2013) Morel-Lavallee Lesion in Children. World Journal of Emergency Surgery, 8, 60. http://dx.doi.org/10.1186/1749-7922-8-60

[27] Lamyman, M.J., Baden, J.M. and Reid, C.D. (2009) The Diagnosis and Management of an Expanding Post-Traumatic Soft Tissue Cyst of the Hip and Groin. Journal of Plastic, Reconstructive \& Aesthetic Surgery, 62, e394-e397. http://dx.doi.org/10.1016/j.bjps.2008.01.027

[28] Kontis, E., Vezakis, A., Psychogiou, V., Kalogeropoulos, P., Polydorou, A. and Fragulidis, G. (2015) Morel-Lavallée Lesion: Report of a Case of Unknown Mechanism. Case Reports in Surgery, 2015, Article ID: 947450. http://dx.doi.org/10.1155/2015/947450

[29] Nair, A.V., Nazar, P., Sekhar, R., Ramachandran, P. and Moorthy, S. (2014) Morel-Lavallée Lesion: A Closed Degloving Injury That Requires Real Attention. Indian Journal of Radiology and Imaging, 24, 288-290. http://dx.doi.org/10.4103/0971-3026.137053

[30] Moriarty, J.M., Borrero, C.J. and Kavanagh, E.C. (2011) A Rare Cause of Calf Swelling: The Morel-Lavallee Lesion. Irish Journal of Medical Science, 180, 265-268. http://dx.doi.org/10.1007/s11845-009-0386-5

[31] Anakwenze, O.A., Trivedi, V., Goodman, A.M. and Ganley, T.J. (2011) Concealed Degloving Injury (the MorelLavallée Lesion) in Childhood Sports. Journal of Bone \& Joint Surgery, 93, e148. http://dx.doi.org/10.2106/JBJS.K.00219

[32] Palacio, E.P., Di Stasi, G.G., Lima, E.H., Mizobuchi, R.R., Júnior, A.D. and Galbiatti, J.A. (2015) Results from Surgical Treatment of Morel-Lavallée Lesions: Prospective Cohort Study. Revista Brasileira de Ortopedia, 50, 148152. http://dx.doi.org/10.1016/j.rbo.2014.03.003 
[33] Dodwad, S.N., Niedermeier, S.R., Yu, E., Ferguson, T.A., Klineberg, E.O. and Khan, S.N. (2015) The Morel-Lavallée Lesion Revisited: Management in Spinopelvic Dissociation. The Spine Journal, 15, e45-e51.

http://dx.doi.org/10.1016/j.spinee.2013.08.023

[34] Efrimescu, C.I., McAndrew, J. and Bitzidis, A. (2012) Acute Lumbar Morel-Lavallee Haematoma in a 14-Year-Old Boy. Emergency Medicine Journal, 29, 433. http://dx.doi.org/10.1136/emermed-2011-200660

[35] Nickerson, T., Zielinski, M., Jenkins, D. and Schiller, H.J. (2014) The Mayo Clinic Experience with Morel Lavallee Lesions: Establishment of a Practice Management Guideline. Journal of Trauma and Acute Care Surgery, 76, 493-497. http://dx.doi.org/10.1097/TA.0000000000000111 